\title{
A (in)efetividade da justiça criminal brasileira Uma análise do fluxo de justiça dos homicídios no Distrito Federal
}

\author{
The (in)effectiveness of the Brazilian criminal justice \\ An analysis of the homicide justice flow in the Federal District
}

Arthur Trindade M. Costa*

\begin{abstract}
Resumo: Embora recentes no Brasil, os estudos sobre fluxo de justiça criminal têm se tornado mais frequentes. Assim, na última década aumentou o número de pesquisas que buscam analisar as formas e dinâmicas como o Sistema de Justiça Criminal (SJC) processa as ocorrências criminais. Alguns estudos buscaram analisar os principais gargalos entre as ocorrências criminais e as sentenças judiciais. Outros estudos analisaram os tempos de tramitação dos processos no sistema de justiça criminal em São Paulo. Apesar da variedade de fontes, metodologias, de forma geral, esses estudos têm analisado o funcionamento do sistema de justiça criminal brasileiro a partir da sua eficiência. Ou seja, avaliam a (in)capacidade do sistema de processar adequadamente toda a demanda por punição. Pouco tem sido discutido sobre a efetividade da punição, suas causas e efeitos. Neste artigo, discutimos a baixa efetividade do sistema de justiça criminal a partir da análise do fluxo de justiça dos homicídios no Distrito Federal.
\end{abstract}

Palavras-chave: Fluxo de justiça criminal. Sistema de justiça criminal. Homicídios. Efetividade. Distrito Federal.

\begin{abstract}
Although recent in Brazil, studies on criminal justice flow have become more frequent. Thus, the number of studies that examine ways and dynamic of the criminal justice system (SJC) processing the criminal activities increased significantly in the last decade. Some studies have analyzed the main obstacles between criminal activities and judicial sentences, while others focused on the duration of the processes in the criminal justice system. Despite the variety of sources and methodologies, these studies in general have examined the functioning of the Brazilian criminal justice system under the perspective of its efficiency. That is, they evaluated the system's ability to properly process the entire demand for punishment. Little has been discussed about the effectiveness of punishment, its causes and effects. In this article, we discuss the low effectiveness of the criminal justice system on the base of the analysis of homicides justice flow in the Brazilian Federal District.
\end{abstract}

Keywords: Criminal justice caseflow. Criminal justice system. Homicides. Effectiveness. Federal District.

\footnotetext{
* Doutor em Estudos Comparados sobre as Américas pela UnB (Brasília, DF, Brasil), professor de Sociologia da Universidade de Brasília e pesquisador do CNPq <arthurtmcosta@gmail.com>.
} 


\section{Introdução}

Embora recentes no Brasil, os estudos sobre fluxo de justiça criminal têm sido cada vez mais frequentes. Desde 1988, com trabalho pioneiro de Edmundo Campos Coelho (1988), temos verificado o aumento do número de pesquisas que buscam analisar as formas e dinâmicas como o sistema de justiça criminal processa as ocorrências criminais. Alguns destes estudos buscaram analisar os principais gargalos entre as ocorrências criminais e as sentenças judiciais. Partindo de diferentes fontes e valendo-se de metodologias variadas Soares et al. (1996), Cano (2006), Misse e Vargas (2007) e Ribeiro (2009) analisaram o fluxo de justiça dos homicídios no Rio de Janeiro. Analisando diferentes tipos de crimes Adorno (1994, 2008), Vargas (2004) estudaram o fluxo de justiça no estado de São Paulo e no município de Campinas respectivamente. Também foram realizadas pesquisas em Florianópolis (Rifiotis, 2006), Belo Horizonte (Sapori, 2007) e Recife (Ratton e Cireno, 2007).

Outros estudos analisaram os tempos de tramitação dos processos no sistema de justiça criminal em São Paulo (Adorno e Pasinato, 2007 e 2008), Rio de Janeiro (Ribeiro, 2009), Belo Horizonte (Batitucci e Cruz 2006), Florianópolis (Ruschel, 2006), Recife (Ratton e Cireno, 2007) e Campinas (Vargas e Zilli, 2008). De forma geral, estas pesquisas compararam os tempos de processamento dos processos judiciais nas diferentes instituições que compõem o sistema de justiça criminal.

Apesar da variedade de fontes, metodologias, de forma geral, esses estudos têm analisado o funcionamento do sistema de justiça criminal brasileiro com foco principal na sua eficiência. Ou seja, as atenções têm se concentrado em avaliar a capacidade do sistema de processar adequadamente toda a demanda por punição. Entretanto, pouco tem sido discutido sobre a efetividade da punição, suas causas e efeitos. Noutras palavras, na forma que o sistema de justiça criminal processa não todas as ocorrências, mas apenas aquelas que foram selecionadas pelos policiais e promotores. Neste artigo, discutimos a baixa efetividade do sistema de justiça criminal a partir da análise do fluxo de justiça dos homicídios no Distrito Federal.

\section{A pesquisa}

Concentramos os trabalhos no levantamento e análise dos dados estatísticos sobre os inquéritos policiais instaurados a partir das ocorrências de homicídios dolosos registrados pela Polícia Civil do Distrito Federal no ano de 2004. Para isto, utilizamos as informações disponíveis no sistema de informações do Tribunal de Justiça do Distrito Federal e Territórios (TJDFT), 
do Ministério Público do Distrito Federal e Territórios (MPDFT) e da própria Polícia Civil.

Foram analisados os processos judiciais criminais do crime de homicídio doloso, transitados em julgado, arquivados no Distrito Federal, cujos inquéritos policiais foram instaurados em 2004 na mesma unidade federativa. Consideramos tanto aqueles inquéritos que tiveram início após a notificação da ocorrência numa delegacia de polícia, como os inquéritos que se iniciaram pela prisão em flagrante dos acusados.

Embora os estudos de fluxo de justiça criminal sejam relativamente novos no Brasil, existem variadas formas de montagem das bases de dados, conforme apontam Misse e Vargas (2007). Elas podem ser montadas a partir do levantamento transversal de informações existentes em diferentes instituições do sistema de justiça criminal. Outra possibilidade é acompanhar longitudinalmente o fluxo de pessoas ou papeis no sistema. Dada a dificuldade de acesso aos documentos produzidos pelas polícias, algumas pesquisas têm se valido de uma "abordagem longitudinal retrospectiva". Neste caso, os dados são levantados de trás para frente. Ou seja, elege-se como base o ano do julgamento (ou arquivamento) dos processos relativos a um tipo específico de crime. Os dados são produzidos a partir da análise dos processos selecionados.

Neste estudo adotamos uma "abordagem longitudinal prospectiva". Analisamos a tramitação dos processos ao longo do sistema de justiça criminal, entretanto acompanhamos o fluxo de justiça do início para o final. Elegemos como base o ano de instauração dos inquéritos policiais referentes aos crimes de homicídios dolosos. A partir de uma relação de inquéritos fornecida pela Corregedoria Geral da Policia Civil do Distrito Federal, buscamos os respectivos processos que estes inquéritos se converteram. A partir desta listagem dos processos, fomos aos arquivos do Tribunal de Justiça do Distrito Federal e Territórios e coletamos informações dos processos já arquivados.

A Polícia Civil do Distrito Federal registrou 556 homicídios no Distrito Federal em 2004, dos quais 311 originaram processos judiciais. Destes 311 processos, 87 constam como arquivados e possuem dados de arquivo no sítio do Tribunal de Justiça do Distrito Federal e Territórios. Os processos arquivados encontram-se distribuídos em 10 das 12 circunscrições judiciárias do Distrito Federal.

\section{Eficiência, eficácia e efetividade da justiça criminal}

Neste artigo, tomo a eficiência do sistema de justiça criminal como a sua capacidade de responder às demandas por punição. Ou seja, eficiência diz respeito à capacidade do sistema de justiça criminal de processar e punir todos 
os crimes registrados pela polícia. Para aferi-la, os pesquisadores(as), via de regra, buscam relacionar no número de Boletins de Ocorrência (BO's) de um dado crime e o número de sentença condenatórias.

De forma geral, a incipiente literatura nacional sobre fluxo de justiça criminal tem destacado o elevado grau de ineficiência do sistema de justiça criminal. Ou seja, a grande maioria dos crimes cometidos não são processados pela justiça. As duas causas principais para sua baixa eficiência seriam: a) a incapacidade das polícias brasileiras (especialmente as polícias civis) em realizar a investigação policial e elaborar adequadamente o inquérito policial e b) a morosidade da justiça brasileira para processar em tempo hábil os crimes apurados pela polícia e denunciados pelo Ministério Público.

A eficácia do Sistema de Justiça Criminal, por sua vez, refere-se aos efeitos da punição sobre as ocorrências criminais. Geralmente, a eficácia é mensurada pelos seus efeitos sobre a taxa de incidência de determinado crime. A eficácia do sistema de justiça criminal diz respeito a sua capacidade dissuasória para impedir novos crimes. Para aferi-la, comparam-se as variações nas taxas de condenação e com as flutuações nas taxas criminais. De forma geral, tais critérios buscam relacionar policiamento, punição e criminalidade. Fazem isso a despeito dos estudos que têm mostrado o reduzido impacto das estratégias de policiamento nos indicadores de criminalidade (Bayley, 1998).

Já a efetividade do sistema de justiça criminal refere-se a sua capacidade de processar, não todas as demandas, mas apenas aquelas selecionadas pelos seus operadores. Ou seja, o conceito de efetividade implica no reconhecimento da seletividade existente no sistema de justiça criminal, bem como destaca seu caráter simbólico. Das três formas de avaliação do sistema de justiça criminal, seguramente a efetividade do sistema de justiça criminal é a que tem sido a menos discutida no Brasil.

Emile Durkheim foi um dos primeiros cientistas sociais a elaborar uma teoria da punição. Entretanto, suas reflexões sobre o tema geralmente são tomadas no sentido mais simples possível. Reputa-se a ele o rompimento com a criminologia clássica que se assentava no estudo do crime, tomando-o de forma absoluta. Durkheim rompe com esta visão simplificada sobre crime ao afirmar que o crime é definido pela sanção que recebe e não pelo comportamento que revela.

De fato, o pensamento de Durkheim produziu uma importante ruptura com a criminologia clássica, mas sua teoria da punição não se restringe a isto. Para ele, a punição era uma instituição conectada aos valores mais profundos da sociedade. A sanção penal era um exemplo tangível daquilo que ele chamou de "consciência coletiva". 
A existência de fortes vínculos de solidariedade moral é a condição necessária para a punição. Noutras palavras, a punição resulta da reafirmação e fortalecimento desses vínculos sociais. Para o sociólogo francês, os crimes são atos que violam a consciência coletiva e por causa disso geram uma reação punitiva. Quando trata do estado de anomia, Durkheim afirma que esta é consequência da fragilidade da estrutura moral da sociedade (consciência coletiva), incapaz de regular as relações sociais.

Aqui está o caráter distintivo da sua teoria da punição. Ao invés de tomar a pena pelo seu aspecto instrumental, como muitos outros o fazem, Durkheim enfatiza o caráter moral da punição. Para ele, a punição é antes de tudo um processo moral e, por que não dizer, político. A punição não é tomada como instrumento de controle social, mas sim como mecanismo de governança. Muito mais do que sua dimensão criminal, Durkheim enfatiza seus aspectos morais e políticos. As dificuldades de punir os crimes mina a força da "estrutura moral" e leva a sua "desmoralização". Noutras palavras, a impunidade corroí a soberania e a autoridade de uma ordem legal, bem como enfraquece os poderes que a suportam. Portanto, a punição não é apenas um instrumento de controle da criminalidade, mas sim, e eu diria principalmente, um mecanismo simbólico de reafirmação da ordem política.

\section{Os inquéritos policiais sobre homicídios no Distrito Federal}

Entre 2003 e 2007 foram instaurados no Distrito Federal 3084 inquéritos policiais para apurar ocorrências de homicídios dolosos. Destes, 2753 foram instaurados através de portaria, para averiguar a autoria e materialidade do crime. Outros 331 inquéritos foram instaurados a partir da prisão em flagrante dos supostos agressores, conforme mostra a tabela 1.

Tabela 1. Inquéritos policiais: portaria e prisões em flagrante homicídios dolosos 2003-2004

\begin{tabular}{lcccccc}
\hline & $\mathbf{2 0 0 3}$ & $\mathbf{2 0 0 4}$ & $\mathbf{2 0 0 5}$ & $\mathbf{2 0 0 6}$ & $\mathbf{2 0 0 7}$ & Total \\
\hline Portaria & 568 & 556 & 523 & 540 & 566 & 2753 \\
Flagrantes & 65 & 69 & 72 & 61 & 64 & 331 \\
Total & 633 & 625 & 595 & 601 & 630 & 3084 \\
\hline
\end{tabular}

Fonte: PCDF.

Os estudos têm apontado um fraco desempenho das polícias brasileiras na elucidação dos crimes de homicídios (ver quadro 1). De modo geral, buscou-se aferir o desempenho policial a partir da comparação das 
taxas de elucidação, ou seja, da razão entre os inquéritos esclarecidos e os crimes registrados. No Distrito Federal, chama atenção a atenção do elevado número de inquéritos esclarecidos. Ou seja, o grande número de inquéritos cujo relatório final confirmou a ocorrência do crime de homicídio e apontou $\mathrm{o}(\mathrm{s})$ nome(s) dos supostos agressores. Conforme mostra a tabela 2, ao todo foram esclarecidos 1915 inquéritos no Distrito Federal, ou seja, 69,1\% dos casos de homicídios.

Quadro 1. Taxa de esclarecimento de homicídios: casos selecionados

\begin{tabular}{|l|c|c|c|}
\hline \multicolumn{1}{|c|}{ Pesquisa } & UF & Período & $\begin{array}{c}\text { Taxa de } \\
\text { elucidação }\end{array}$ \\
\hline Soares (1996) & RJ & 1992 & $8 \%$ \\
\hline Rifiotis (2007) & SC & $2000-2006$ & $43 \%$ \\
\hline Ratton e Cireno (2007) & PE & $2003-2005$ & $15 \%$ \\
\hline Misse e Vargas (2007) & RJ & $2000-2005$ & $14 \%$ \\
\hline Sapori (2007) & MG & $2000-2005$ & $15 \%$ \\
\hline Costa (2009) & DF & $2003-2007$ & $69 \%$ \\
\hline
\end{tabular}

Fontes: Ribeiro (2009) e Costa (2009).

Tabela 2. Inquéritos policiais - portaria e homicídios dolosos, 2003-2007

\begin{tabular}{lcccccr}
\hline & $\mathbf{2 0 0 3}$ & $\mathbf{2 0 0 4}$ & $\mathbf{2 0 0 5}$ & $\mathbf{2 0 0 6}$ & $\mathbf{2 0 0 7}$ & Total \\
\hline Solucionados & 407 & 415 & 407 & 337 & 349 & 1915 \\
Em apuração & 179 & 141 & 116 & 203 & 217 & 856 \\
Total & 568 & 556 & 523 & 540 & 566 & 2771 \\
\hline
\end{tabular}

Fonte: PCDF.

Os motivos deste desempenho extraordinário ainda precisam ser explicados. A variável "tempo" não parece ser capaz de explicar sozinha as taxas de elucidação de homicídios no Distrito Federal. O maior percentual de esclarecimento ocorreu entre os inquéritos instaurados em 2005 (77,8\%), índice superior aos apresentados em 2004 e 2003. Os aspectos organizacionais tampouco explicam este êxito. Até 2006, as investigações eram conduzidas inicialmente pelas delegacias circunscricionais. A delegacia de homicídios assumia os casos mais complicados. A partir de 2007, foi criada a divisão de homicídios. Apesar desta mudança organizacional, o percentual de inquéritos solucionados manteve-se estável. 
Embora possua uma polícia técnica muito bem estruturada, tanto em termos pessoais quanto em equipamentos, é pouco provável que isto explique o desempenho das investigações sobre homicídios dolosos. Segundo entrevistas realizadas com agentes, delegados, peritos, promotores e juízes, boa parte do trabalho de perícia está voltado para confirmar a materialidade do crime. Pouco trabalho pericial é dedicado à verificação da autoria do crime. Nesta pesquisa, trabalhamos com a hipótese de que o desempenho das investigações sobre homicídios dolosos no Distrito Federal está relacionado ao tipo de conflito que gerou estas mortes bem como ao padrão de relação que se estabelece entre a polícia e a população.

O Distrito Federal também apresenta um número grande de prisões em flagrante nos casos de homicídios dolosos. Entre 2003 e 2007 foram instaurados 331 inquéritos a partir da prisão em flagrante do(s) suposto(s) agressor(es). A maior parte destas prisões em flagrante foi realizada pela Polícia Civil do Distrito Federal, conforme mostra a tabela 3.

Tabela 3. Inquéritos policiais: portarias e prisões em flagrante homicídios dolosos, 2003-2007

\begin{tabular}{lrrrrrr}
\hline & $\mathbf{2 0 0 3}$ & $\mathbf{2 0 0 4}$ & $\mathbf{2 0 0 5}$ & $\mathbf{2 0 0 6}$ & $\mathbf{2 0 0 7}$ & Total \\
\hline Portaria & 568 & 556 & 523 & 540 & 566 & 2753 \\
Flagrantes & 65 & 69 & 72 & 61 & 64 & 331 \\
Total & 633 & 625 & 595 & 601 & 630 & 3084 \\
\hline
\end{tabular}

Fonte: PCDF.

\section{Os tempos do fluxo de justiça criminal no Distrito Federal}

A pesquisa também buscou analisar os tempos de tramitação no sistema de justiça criminal do Distrito Federal dos inquéritos e processos judiciais sobre os crimes de homicídios. Em 80\% dos inquéritos analisados, a Polícia Civil do Distrito Federal registrou o Boletim de Ocorrência no mesmo dia em que aconteceu o crime. Entre o registro do Boletim de Ocorrência e a instauração do inquérito a polícia do Distrito Federal gasta em média 8 dias. Certamente este tempo reduzido decorre das Normas Gerais de Ação da Polícia Civil do Distrito Federal que determinam a instauração de inquérito policial em todos os casos de homicídios dolosos. Nestes casos não é realizada uma investigação preliminar como ocorre em outros tipos de crime.

Em média, a Polícia Civil do Distrito Federal leva 300 dias para concluir os inquéritos policiais sobre homicídios dolosos. Este prazo, entretanto, varia 
consideravelmente entre os inquéritos instaurados por portaria e aqueles iniciados pela prisão em flagrante do autor. Conforme mostra a tabela 4, nos casos de instauração por portaria o tempo médio para conclusão do inquérito policial é de 412 dias enquanto nos casos de flagrante é de 6 dias.

Tabela 4. Tempo do inquérito policial: flagrante $\times$ portaria

\begin{tabular}{lrcc}
\hline & Média & N & Desvio padrão \\
\hline Flagrante & 6,3 & 22 & 5,7 \\
Portataria & 412,6 & 58 & 408,2 \\
Total & 300,9 & 80 & 391,9 \\
\hline
\end{tabular}

Fonte: TJDFT.

No Distrito Federal, uma vez concluídos, os inquéritos policiais não são remetidos diretamente para a justiça. Antes eles são encaminhados à Corregedoria Geral da Polícia Civil para a correição. Isto ocorre em 13 dias, na média. Só depois de serem analisados do ponto de vista da forma jurídica é que os inquéritos são remetidos à justiça. Em média este processo leva 16 dias. Ou seja, antes de serem enviados à justiça, os inquéritos policiais levam cerca de 30 dias tramitando entre a delegacia, a corregedoria e o cartório do tribunal. Entre o recebimento no cartório e o envio para o Ministério Público, há um prazo médio de 11 dias.

O Ministério Público leva cerca de 131 dias entre o recebimento do inquérito e a emissão do parecer (denúncia, arquivamento ou cotas). Há uma variação quanto à forma de instauração. Nos inquéritos originados por flagrante o tempo médio é de 67 dias e nos casos de portaria, 152 dias, como mostra a tabela 5 .

Tabela 5. Tempo do parecer do Ministério Público: flagrante $\times$ portaria

\begin{tabular}{lccc}
\hline & Média & N & Desvio padrão \\
\hline Flagrante & 67,2 & 21 & 267,1 \\
Portataria & 152,9 & 62 & 292,0 \\
Total & 131,2 & 83 & 286,8 \\
\hline
\end{tabular}

Fonte: TJDFT.

Uma vez recebida a denúncia, o processo leva 293 dias até que o juiz decida pronunciar o acusado ou não. Uma vez feita a pronúncia, o Tribunal do Juri leva cerca de 254 dias julgar os acusados. Diferente da Polícia e do 
Ministério Público, tanto nas varas criminais quanto no Tribunal do Juri, o tempo de tramitação dos processos cujos inquéritos iniciaram por flagrante é ligeiramente maior do que os iniciados por portaria. No caso das varas criminais, aqueles iniciados por flagrantes levam em média 295 dias para tramitar, ao passo que os instaurados por portaria levam 291 dias. No Tribunal do Juri, este padrão se repete: 290 dias para aqueles iniciados por flagrante e 231 para os instaurados por portaria.

Tabela 6. Tempo de pronúncia - justiça criminal: flagrante $\times$ portaria

\begin{tabular}{lccc}
\hline & Média & N & Desvio padrão \\
\hline Flagrante & 295,4 & 21 & 377,3 \\
Portataria & 291,9 & 36 & 266,1 \\
Total & 293,2 & 57 & 308,4 \\
\hline
\end{tabular}

Fonte: TJDFT.

Tabela 7. Tempo de sentença - tribunal do juri: flagrante $\times$ portaria

\begin{tabular}{lccc}
\hline & Média & N & Desvio padrão \\
\hline Flagrante & 290,4 & 19 & 435,8 \\
Portataria & 231,7 & 30 & 253,1 \\
Total & 254,5 & 49 & 332,8 \\
\hline
\end{tabular}

Fonte: TJDFT.

\section{A efetividade da justiça criminal no Distrito Federal}

A efetividade do sistema de justiça criminal pode ser aferida pela relação entre o número de crimes denunciados pelo Ministério Público e o número de condenações determinadas pela justiça. No Distrito Federal, apesar do bom desempenho da Polícia Civil na elucidação dos crimes de homicídios e do baixo tempo de tramitação dos processos judiciais, a efetividade do sistema de justiça criminal é muito próxima daquela apresentada nas outras unidades da federação.

Dentre os 87 processos analisados no Distrito Federal, 64 originaram-se de inquéritos policiais instaurados por portarias da polícia, enquanto 23 são frutos de inquéritos iniciados por atos de prisão em flagrante, conforme mostra a tabela 8 . Do total de inquéritos analisados, 68 (78,2\%) foram denunciados pelo Ministério Público. Do total de inquéritos denunciados pelo Ministério Público, 49 (72,1\%) receberam uma sentença de pronúncia do Juiz Criminal e 
foram encaminhados ao Tribunal do Júri. Dos casos pronunciados, 22 (44,9\%) receberam sentenças condenatórias privativas de liberdade.

\section{Tabela 8. Fluxo de justiça criminal no Distrito Federal - homicídios dolosos, 2004}

\begin{tabular}{lccccccc}
\hline \multicolumn{2}{l}{ Inquérito Policial } & \multicolumn{2}{c}{ Ministério Público } & \multicolumn{2}{c}{ Justiça Criminal } & \multicolumn{2}{c}{ Tribunal do Juri } \\
\hline \multicolumn{2}{c}{$\begin{array}{c}\text { Forma de } \\
\text { instauração }\end{array}$} & \multicolumn{2}{c}{ Denúncia } & \multicolumn{2}{c}{ Pronúncia } & \multicolumn{2}{c}{ Condenação } \\
\hline Flagrante & 24 & Sim & 68 & Sim & 49 & Sim & 22 \\
Portaria & 63 & Não & 19 & Não & 19 & Não & 27 \\
Total & 87 & & 87 & & 68 & & 49 \\
\hline
\end{tabular}

Fonte: TJDFT.

Verificamos, portanto, que apenas 32,4\% (22) das denúncias feitas pelo Ministério Público resultaram na condenação do(s) indiciado(s). Estes números não servem para aferir a qualidade do trabalho da polícia, uma vez que as atuações do Ministério Público, da Justiça Criminal e do Tribunal do Júri também contribuíram para este resultado. Por outro lado, os dados produzidos nos permitem refletir sobre as interações entre três importantes atores do sistema de justiça criminal: o delegado, o promotor e o juiz.

Como sabemos, o promotor é o "titular da ação penal" e, portanto, tem autonomia para julgar se os fatos relatados no inquérito policial devem ou não ser denunciados. Isto implica em dizer que promotor e delegado podem divergir sobre os aspectos jurídicos dos casos apresentados. O mesmo acontece com o juiz criminal, que pode divergir sobre a interpretação do delegado e do promotor e decidir não pronunciar o(s) acusado(s). É importante considerar também que as frequentes trocas de operadores ao longo do fluxo de justiça. Durante o desenvolvimento do inquérito policial podemos encontrar diferentes delegados responsáveis pela condução dos trabalhos. O mesmo vale para o processo judicial. São frequentes as substituições de promotores e juízes no curso da ação penal.

Cada um dos atores (delegados, promotores e juízes), bem como os diferentes operadores do sistema podem apresentar diferentes interpretações quanto à necessidade, validade e suficiência das provas apresentadas no processo. Eles também podem discordar sobre o enquadramento do tipo penal. Essas divergências entre atores e operadores do sistema de justiça criminal será objeto de nossa análise nesta seção. 
Conforme mostra a tabela 9 , em $81(93,1 \%)$ casos o delegado sugeriu no seu relatório final a denúncia da(s) pessoa(s) indiciadas no inquérito. Porém, é interessante notar que em 6 casos $(6,9 \%)$ os delegados responsáveis pelos inquéritos sugeriram o arquivamento do processo, por acharem que não havia provas necessárias para a condenação do(s) acusados(s).

Tabela 9. Relatório final - delegado

\begin{tabular}{lcr}
\hline & Quantidade & \% \\
\hline Arquivamento & 6 & 6,9 \\
Denúncia & 81 & 93,1 \\
Total & 87 & 100,0 \\
\hline
\end{tabular}

Fonte: TJDFT.

Os promotores decidiram pela denúncia em $78,2 \%$ dos casos analisados. Portanto, em $19(21,8 \%)$ casos, promotores e delegados divergiram sobre se as provas (testemunhas, depoimentos, perícias etc.) produzidas no inquérito policial eram necessárias e/ou suficientes para atestar a autoria e a materialidade do crime. Nestes casos, os promotores determinaram que o processo retornasse à polícia. Na linguagem cotidiana dos promotores, "eles decidiram pela baixa". Conforme mostra a tabela 10 , em $47,4 \%$ dos casos, os promotores determinaram que se continuasse a investigação e que fossem feitas novas diligências. Em 26,3\% dos casos, solicitaram esclarecimentos de pontos da investigação e em outros $26,3 \%$ requisitaram que a polícia completasse a documentação apresentada.

Tabela 10. Motivos do pedido de baixa - MP

\begin{tabular}{lcc}
\hline & Quantidade & \% \\
\hline Continuar investigação & 9 & 47,4 \\
Esclarecer pontos & 5 & 26,3 \\
Completar documentação & 5 & 26,3 \\
Total & 19 & 100,0 \\
\hline
\end{tabular}

Fonte: TJDFT.

Mesmo nos casos onde foi apresentada denúncia, houve divergências entre as interpretações de delegados e promotores. Em 23\% dos casos, os promotores concluíram que os inquéritos apresentavam elementos jurídicos 
necessários e suficientes para a condenação dos acusados, mas divergiram parcialmente dos delegados sobre aspectos como a tipificação penal, a coautoria e mesmo sobre a materialidade dos casos. De qualquer forma, delegados e promotores concordaram integralmente em mais da metade dos casos $(55,2 \%)$, conforme mostra a tabela 11 .

Tabela 11. Parecer do ministério público

\begin{tabular}{lcc}
\hline & Quantidade & $\mathbf{\%}$ \\
\hline Arquivamento & 19 & 21,8 \\
Denúncia integral & 48 & 55,2 \\
Denúncia parcial & 20 & 23,0 \\
Total & 87 & 100,0 \\
\hline
\end{tabular}

Fonte: TJDFT.

Analisando-se os inquéritos policiais, verificamos que em 93,1\% dos casos foram solicitadas perícias. Poucos inquéritos $(6,9 \%)$ foram concluídos sem o ajuntamento de laudos periciais. Em mais da metade dos casos $(55,2 \%)$ foram verificados pelo menos dois laudos periciais. Cerca de $10 \%$ dos casos apresentaram mais de cinco perícias.

Ao todo foram identificados 175 laudos periciais, sendo a perícia da cena do crime a mais frequente $(38,2 \%)$, seguida do exame do Corpo de Delito $(28,6 \%)$ e do exame da arma de fogo $(13,7 \%)$. Também foram verificados exames balísticos, exames imuno-hepatológicos, grafológicos e de resíduos. Entretanto, a existência de laudos periciais no inquérito policial não assegura necessariamente a condenação dos acusados.

$\mathrm{O}$ número de testemunhas ouvidas e relatadas nos inquéritos policiais variou bastante. $\mathrm{O}$ número médio de testemunhas relatadas em cada inquérito foi 5,6 . Em quase $75 \%$ dos casos foram ouvidas até seis testemunhas, conforme mostra a tabela 12. Apenas em um caso não constava o depoimento de nenhuma testemunha.

Constam nos inquéritos 489 depoimentos de testemunhas. Cerca de $75 \%$ das pessoas ouvidas nos inquéritos testemunharam sobre os fatos ocorridos. Apenas 7,5\% das testemunhas foram ouvidas para atestar o caráter dos indiciados. Ainda sobre as testemunhas, cerca de $75 \%$ tinham algum tipo de relação com a vítima ou com o indiciado. Em $31 \%$ dos casos, as testemunhas eram conhecidas da vítima e em $17 \%$ eram conhecidas do indiciado. Chama a atenção o elevado percentual de policiais ouvidos nos inquéritos policiais como testemunhas, $25 \%$. 
Tabela 12. Número de testemunhas

\begin{tabular}{|c|c|c|c|}
\hline Número & Frequência & $\%$ & $\%$ Acumulada \\
\hline 0 & 1 & 1,2 & 1,1 \\
\hline 1 & 2 & 2,3 & 3,4 \\
\hline 2 & 8 & 9,2 & 12,6 \\
\hline 3 & 20 & 23,0 & 35,6 \\
\hline 4 & 12 & 13,8 & 49,4 \\
\hline 5 & 9 & 10,3 & 59,8 \\
\hline 6 & 13 & 14,9 & 74,7 \\
\hline 7 & 5 & 5,7 & 80,5 \\
\hline 8 & 2 & 2,3 & 82,8 \\
\hline 9 & 4 & 4,7 & 87,4 \\
\hline 10 & 3 & 3,4 & 90,8 \\
\hline 12 & 2 & 2,3 & 93,1 \\
\hline 14 & 3 & 3,4 & 96,6 \\
\hline 16 & 1 & 1,2 & 97,7 \\
\hline 20 & 2 & 2,3 & 100,0 \\
\hline Total & 87 & 100,0 & \\
\hline
\end{tabular}

Fonte: TJDFT.

Apesar dos inquéritos frequentemente apresentarem laudos periciais e depoimentos de testemunhas como meio de prova, verificamos que a apreensão da arma de fogo é elemento fundamental para a pronúncia e condenação dos indiciados. Em todos os 39 casos que a arma foi apreendida pela polícia, o indiciado foi pronunciado pelo juiz e levado ao Tribunal do Júri para ser julgado.

Tabela 13. Arma presa $\times$ pronúncia

\begin{tabular}{lccc}
\hline & & Arma presa & Pronúncia \\
\hline Arma presa & Correlação & 1 & $-0,46$ \\
& Sig & & 0,674 \\
Pronúncia & N & 87 & 87 \\
& Correlação & $-0,46$ & 1 \\
& Sig & 0,674 & \\
& $\mathrm{~N}$ & 87 & 87 \\
\hline
\end{tabular}


A baixa efetividade do sistema de justiça criminal pode ser explicada por três aspectos: a) diferentes interpretações dos operadores do sistema, b) denúncias realizadas sem a existência de provas suficientes para condenação e c) desconfiança da lisura dos procedimentos de investigação policial.

Como apontamos anteriormente, são frequentes as trocas de operadores ao longo do inquérito policial e do processo criminal. Se por um lado, as trocas de delegados atrapalham a elucidação dos crimes, por outro, as trocas de juízes acabam por dilatar os tempos de tramitação dos processos. As constantes trocas de promotores, por sua vez, afetam a efetividade do sistema de justiça criminal, dado que cada promotor pode interpretar as provas existentes nos inquéritos policiais de forma distinta. Não são raros os casos onde um promotor sugere ao juiz o arquivamento do processo por discordar da denúncia inicial feita por outro colega.

Esta situação é agravada quando alguns promotores seguem o princípio "em dúvida pró sociedade". Ou seja, mesmo sem as provas necessárias e suficientes para condenação é apresentada denúncia na expectativa de que ao longo do processo surjam novos elementos probatórios. Se isso não ocorrer, pede-se o arquivamento do processo. Obviamente esta prática contraria o princípio da "presunção de inocência", ou seja, ninguém é considerado culpado a menos que prove o contrário. Aqui vale a ideia de que mesmo sem provas, alguém pode ser culpado.

Finalmente, percebe-se uma grande desconfiança por parte de promotores e juízes com relação aos procedimentos de investigação adotados pela polícia. São frequentes as denúncias de violências e arbitrariedades cometidas por policiais. Além disso, ainda são frágeis os mecanismos de controle da atividade policial. No Distrito Federal, não existem normas internas de conduta a serem seguidas no curso da investigação. A Corregedoria da Polícia Civil e o Núcleo de Controle Externo da Atividade Policial do Ministério Público concentram-se na fiscalização dos aspectos formais do inquérito policial, dando pouca atenção às práticas sociais relacionadas à investigação policial.

Em função disso, juízes e promotores tendem a desconfiar das provas produzidas pela polícia, especialmente das testemunhas e depoimentos apresentados nos inquéritos.

\section{Conclusão}

A análise do caso do Distrito Federal permite avançar nas reflexões sobre o funcionamento do sistema de justiça criminal brasileiro. As mazelas do sistema brasileiro não referem-se apenas ao mal funcionamento da polícia ou à lentidão da justiça. A despeito da maior eficiência da Polícia 
Civil no esclarecimento dos homicídios, a efetividade do sistema é baixa. Apenas 32,4\% dos casos denunciados pelo Ministério Público resultaram em sentença condenatória. Ou seja, mesmo nos casos esclarecidos pela polícia e denunciados pelo Ministério Público, a resposta do sistema de justiça criminal é pouco efetiva.

Esta baixa efetividade é resultado das ideias e práticas sociais que permeiam a atuação de juízes e promotores. Isso é resultado da falta de uniformidade de procedimentos e avaliações feitas pelos membros do Ministério Público. Além disso, alguns promotores apresentam denúncias mesmo sabem que as provas existentes no inquérito são insuficientes para uma condenação. Por fim, há enorme desconfiança entre promotores, juízes e advogados de defesa sobre a legalidades dos procedimentos de investigação utilizados pela polícia.

O resultado disso é que mesmo nos casos selecionados pela polícia e pelo Ministério Público, a resposta do sistema de justiça criminal é insatisfatória. Ou seja, do ponto de vista simbólico, o funcionamento do sistema de justiça criminal também deixa a desejar. Isso acentua mais ainda a sensação de impunidade que parece estar disseminada na sociedade brasileira.

Nosso estudo se concentrou na análise do fluxo de justiça dos homicídios no Distrito Federal. Supostamente as taxas de efetividade dos crimes violentos tendem a ser maiores do que dos crimes contra o patrimônio. Além disso, a efetividade não depende apenas do desempenho das instituições que compõem o sistema, mas também da sua lógica de funcionamento, bem como do contexto político no qual o sistema está inserido.

\section{Referências}

ADORNO, Sérgio. Políticas públicas de segurança e justiça penal. Cadernos Adenauer, v. 9, p. 9-27, 2008.

ADORNO, Sérgio. Crime, justiça penal e desigualdade jurídica: os crimes que se contam no Tribunal do Júri. Revista USP, v. 21, p. 132-51, 1994.

ADORNO, Sérgio; PASINATO, Wania. A justiça no tempo, o tempo da justiça. Tempo Social, v. 19, p. 131-155, 2007.

ADORNO, Sérgio; PASINATO, Wânia. Violência e impunidade penal: da criminalidade detectada à criminalidade investigada. Dilemas, v. 3, p. 51-84, 2010.

BATITUCCI, Eduardo; CRUZ, Marcus Vinícius. Fluxo do crime de homicídio no sistema de justiça criminal de Minas Gerais. $30^{\circ}$ Encontro da Anpocs, Caxambu, MG, 2006.

BAYLEY, D. What works in policing. New York: Oxford University Press, 1998.

CANO, Ignácio. Mensurando a impunidade no sistema de justiça criminal do Rio de Janeiro. $3^{\circ}$ Congresso de Ciência Política, Campinas, SP, 2006. 
COELHO, E. C. A oficina do diabo e outros estudos sobre criminalidade. Rio de Janeiro: Record, 1988.

COSTA, Arthur. O inquérito policial no Distrito Federal. Cadernos Temáticos da Conseg, v. 6, p. 53-64, 2009.

DURKHEIM, E. Da divisão social do trabalho. São Paulo: Martins Fontes, 1999.

MISSE, Michel; VARGAS, Joana. O fluxo do processo de incriminação no Rio de Janeiro na década de 50 e no período de 1997-2001: comparação e análise. 13ํㅡㅁ Congresso Brasileiro de Sociologia, Recife, PE, 2007.

RATTON, José Luis; CIRENO, Fernando. Violência endêmica: homicídios na cidade do Recife - dinâmica e fluxo no sistema de justiça criminal. Revista do Ministério Público de Pernambuco, v. 6, p. 17-157, 2007.

RIBEIRO, Ludmila. Administração da justiça criminal na cidade do Rio de Janeiro: uma análise dos casos de homicídios. Iuperj, Tese de Doutorado em Sociologia, 2009.

RIFIOTIS, Teophilos. Fluxo da justiça criminal em casos de homicídios dolosos na Região Metropolitana de Florianópolis entre os anos de 2000 e 2003. 2006. Mimeo.

RUSCHEL, Aírton. Análise do tempo dos processos penais de homicídios no Florianópolis. Ufsc, Dissertação de Mestrado em Antropologia Social, 2006.

SAPORI, Luis Flávio. Segurança pública no Brasil: desafios e perspectivas. Rio de Janeiro: Ed. FGV, 2007.

SILVA, Christyne. Relacionamento entre controle interno e externo da PMDF. UnB, Dissertação de Mestrado em Sociologia, 2008.

SKOLNICK, Jerome; BAYLEY, David. Policiamento comunitário: questões e práticas através do mundo. São Paulo: Edusp, 2002.

SOARES, Luiz Eduardo. Violência e politica no Rio de Janeiro. Rio de Janeiro: Relume-Dumará, 1996.

VARGAS, Joana. Estupro: que justiça? Fluxo do funcionamento e análise do tempo da justiça criminal para o crime de estupro. Iuperj, Tese de Doutorado em Sociologia, 2004.

VARGAS, Joana; ZILLI, Luis Felipe. Uma abordagem empírica do inquérito policial: o caso de Belo Horizonte. In: Michel Misse, O inquérito policial no Brasil: uma pesquisa empírica. Rio de Janeiro: Booklink, 2010.

Recebido em: 23 abr. 2014

Aprovado em: 17 out. 2014

Autor correspondente:

Arthur Trindade M. Costa

UnB - Instituto de Ciências Sociais

Campus Universitário Darcy Ribeiro, ICC Norte, Asa Norte

70910-900, Brasília, DF 